\title{
СОЗНАТЕЛЬНОЕ И БЕССОЗНАТЕЛЬНОЕ: К ИСТОРИОГРАФИИ ВОПРОСА
}

\author{
Д. М. Магаррамов
}

Региональный Центр этнополитических исследований Дагестанского научного центра Российской академии наук

Аннотация: Текст доклада автора на Всероссийской научной конференции «Культура между Логосом и Мифом: к проблеме бессознательного (к 80-летию А. Э. Воскобойникова)», которая прошла в Московском гуманитарном университете 26-27 октября 2017 года.

Ключевые слова: сознательное; бессознательное; историография; история психологии; история философии; Анатолий Эммануилович Воскобойников

\section{THE CONSCIOUS AND UNCONSCIOUS: ON THE HISTORIOGRAPHY OF THE ISSUE}

\author{
D. M. Magarramov
}

Regional Centre of Ethnopolitical Researches, Dagestan Scientific Centre, Russian Academy of Sciences

Аннотация: The text of the author's speech at the All-Russian Scientific Conference "Culture between Logos and Myth: on the Issue of the Unconscious (dedicated to the 80th anniversary of A. E. Voskoboynikov)", which was held at Moscow University for the Humanities on 26-27 October 2017.

Ключевые слова: conscious; unconscious; historiography; history of psychology; history of philosophy; Anatoly Emmanuilovich Voskoboynikov

Обращение к проблеме историографии сознательного и бессознательного актуально в силу необходимости научного анализа литературы, посвящённой этой проблеме. Такая работа может в значительной степени облегчить проведение другими авторами исследований, посвящённых этому вопросу. Очевидно, что систематизация источников даёт ясную картину о тех исследователях, которые занимались и занимаются этой проблемой и, в то же самое время, известным становится те аспекты, которые нашли научное разрешение в рамках научных статей, докладов, монографий и др. исследованиях. 
Следует отметить, что одним из известных современных российских учёных-философов и социальных психологов, который занимался проведением фундаментальных исследований по проблеме сознательного и бессознательного, является доктор философских наук, профессор Воскобойников Анатолий Эммануилович. Он ещё с середины 1970-х гг. выступал с циклами лекций по проблеме бессознательного в вечернем университете при Госкино и Союзе кинематографистов, семинарах артистов балета Большого театра, режиссерских семинарах во Всероссийском театральном обществе и др.

На всем протяжении своей научной деятельности он развивает концепцию, согласно которой определяющую роль в эволюционно-историческом развитии человека играют синергетические взаимодействия, обладающие потенциальными возможностями преодоления расщепленности и деструктивной противоречивости людей.

Он является автором целого ряда фундаментальных научных трудов, включая «Бессознательное и сознательное в человеке» (1997) и многочисленных статей по психоанализу, неофрейдизму, философской антропологии, духовной культуре и др.

Наиболее глубоким научным трудом, в рамках которого нашли своё научное разрешение ключевые проблемы сознательного и бессознательного, является его докторская диссертация. Все авторские обобщения и выводы, сформулированные в ней, являются крайне важными и востребованными в условиях, когда в нашей стране идут процессы модернизации всех сфер общественной жизни. Вряд ли кто-то сейчас станет возражать против того, что во времена не столь отдаленные многими отвергалось: «Бессознательное играет важную роль не только во внутреннем мире человека, но и во взаимодействиях людей в больших и малых группах. Неразумно пренебрегать влиянием бессознательного даже в самых сложных социальных явлениях».

В статье «Бессознательное и сознательное в художественной культуре» автор умозаключил, что глубокий эстетический образ или талантливое произведение искусства всегда сопряжены со смысловой многозначностью, а их создание - с художественной интуицией, вдохновением, воображением. В процессе творчества научная интуиция работает на базе дискретной, дискурсивной информации, а художественная - порождает результат, имеющий континуальную информативную мощность. Таким образом, сформулированный автором вывод позволяет обогатить духовный мир человека, найти в нём ранее неизвестные, потаённые грани, на которые раньше исследователи не обращали внимание. Именно вскрытие ранее неизвестных сегментов психического, его роли в постижении искусства и культуры есть основа той новации, которую мы видим в этом научном труде А. Э. Воскобойникова. 
Научные труды Московского гуманитарного университета 2018 № 3

В другой своей научной статье А. Э. Воскобойников сформулировал такой достаточно глубокий вывод: в основе психической жизни человека лежит филогенетически врожденное бессознательное. С ним связано онтогенетически сформировавшееся бессознательное - подсознание. Образуя единое целое, эти два типа бессознательного служат фундаментом для предсознания и сознания. Таким образом, подсознание и бессознательное, действительно являются интегративными частями сознания, требуют нового осмысления в свете экономических, политических, социальных и духовно-нравственных трансформаций, происходящих в современном российском обществе. Такая научная работа, как важная составная часть научной деятельности, систематически проводится А. Э. Воскобойниковым.

Отдельные аспекты проблемы сознательного и бессознательного были отражены учеником А. Э. Воскобойникова С. А. Семедовым в 1994 г. в его диссертации на соискание учёной степени кандидата философских наук. C учётом научных наработок сознательного и бессознательного С. А. Семедов написал более 40 научных трудов, посвящённых проблеме политического ислама. Наиболее фундаментальным и глубоким из них является его монографическое исследование.

Проблемы сознательного и бессознательного в новом тысячелетии стали привлекать возрастающее число российских исследователей. Так, свою монографию В. В. Старавойтов посвятил анализу основных школ «ортодоксального» психоанализа на рубеже XX и XIX вв. В ней не просто исследуется современное состояние психоанализа, но и прослеживается генеалогия, эволюция и взаимное влияние различных его школ. Это необычайно важно для читательской аудитории, поскольку обычно рассматривается либо «классический» (эпохи Фрейда) психоанализ, либо отдельные, чаще прикладные, аспекты современного. Такое целостное исследование предпринято у нас впервые. Автор выходит в область «метапсихологии», обнаруживая корреспондентность школ современного психоанализа различным философским течениям - герменевтике, феноменологии, «философии диалога». Монография посвящена анализу основных школ «ортодоксального» психоанализа на рубеже XX и XXI вв. В ней не просто исследуется современное состояние психоанализа, но и прослеживается генеалогия, эволюция и взаимное влияние различных его школ.

Отдельные аспекты проблемы сознательного и бессознательного нашли отражение в научных статьях целого ряда авторов. Так в своей научной статье Л. Н. Кубашичева отметила, что общая нынешняя социокультурная ситуация - падение нравственности, преступность, межнациональные конфликты, терроризм, безработица и т. д. - способствует обострению неврозов и возникновению явных и скрытых психических расстройств, ко- 
торые по сути дела игнорируются родителями, педагогами, врачами. Из-за перенапряжения в душе ребёнка существует конфликт между неокрепшим сознанием и напористыми бессознательными влечениями. На этом фоне происходят срывы, возникают фобии и комплексы и т. д.

В научной статье А. Макинтайра проведён достаточно глубокий науч-ный анализ понятийно-категориального аппарата анализа проблемы бессознательного. Выдвинутые и подвергнутые автором категории могут быть использованы при проведении социально-философского анализа бессознательного как одно из проявлений известного метода восхождения от конкретного к абстактному, от единичного - к частному.

В своей глубокой по смыслу и содержанию научной статье д. филос. н., профессор, президент Московской межрегиональной психоаналитической ассоциации П. С. Гуревич справедливо отметил, что Фрейд, как известно, в значительной мере был заложником просветительской философии. Э. Фромм в работе «Величие и ограниченность теории Фрейда» отмечает, что научный подвиг австрийского психиатра - в культе истины. Далее он продолжает, что огромную роль в философии сыграло открытие Фрейдом бессознательного. Оно радикально изменило многие сферы философского знания - онтологические, гносеологические, историко-философские.

В статье С. А. Тугуши рассматривается проявление личного и коллективного бессознательного в кинопритчах мастеров разных поколений.

В научной статье И. В. Головачёвой отмечено, что структура и работа сознания трудно поддается словесному выражению, взывая к необходимости метафорического и символического описания. Олдосу Хаксли это прекрасно удавалось. В междисциплинарной работе рассматриваются отнюдь не случайные изменения в топографических моделях сознания, предложенных в произведениях, эссе и письмах Хаксли.

В своей научной статье И. А. Куевда даёт дефиницию сознания, отмечая, что в отечественной философии и психологии наиболее общепринятое определение сознания - свойственный человеку способ отношения к объективной действительности, опосредованный всеобщими формами общественно-исторической деятельности людей. В этой же работе она по-своему раскрывает соотношение понятий «архетип»и «ментальность». Архетипические основы любого менталитета загадочны, так как не находят непосредственного проявления: архетип скрывается, но проявляется через ментальность. Взаимодействие архетипа и менталитета - это одна из форм взаимодействия сознательного и бессознательного.

В коллективной статье Н. Ю. Хусаиновой и А. Р. Гиниятуллиной впервые реализован новый методологический подход к исследованию феномена «психическое состояние» с позиции теории архетипов. И именно поэтому 
Научные труды Московского гуманитарного университета 2018 № 3

приведены разные тексты К.-Г. Юнга, которые призваны и для подтверждения самой нашей идеи, и для того, чтобы наконец-то прекратить множественные исследования психических состояний, выполненных вне учёта влияния архетипов. Архетипы в момент исследования любого психического состояния могут быть либо актуализированными, либо подавленными, и потому по-разному будут влиять на изучаемое психическое состояние. От этого неучитываемого факта выводы исследователей по поводу объекта и предмета своего исследования - ошибочны. Все наблюдаемые и тестируемые состояния несут в себе влияние архетипов, о которых не подозревают исследователи, работающие вне идей юнгианской психологии.

В статье В. Э. Степанова предпринята попытка ответить на вопрос, как в психоанализе рациональная форма может сочетаться с иррациональным содержанием учения. По ходу исследования выявляются причины формирования этого парадокса и указываются основные заблуждения, возникающие при трактовке психоанализа многочисленными комментаторами и последователями.

В своем исследовании Г. В. Голенок провёл различие между понятиями «комплекс» и «архетип» в аналитической психологии, раскрыл интерес Юнга к оккультизму, дал специфическую трактовку архетипа как своеобразного «атома» коллективного бессознательного.

Исследователи Е. М. Уколова и В. Б. Шумский в коллективной статье обосновывают понимание совести как внутренней точки опоры при соотне-сении с самим собой в процессе самодетерминации человека. На основании историко-культурного анализа и представлений современной экзистенциальной психологии показано, что могут быть выделены не только ретроспективно-укоряющая и проспективно-предостерегающая функции совести, но и функция, состоящая в участии совести в формировании стратегии конкретных поступков. Понимание голоса совести как звучащего на этапе принятия решений позволило предложить методические шаги для нахождения аутентичной позиции, которые могут быть использованы в практике повседневности и в психологическом консультировании.

В коллективной статье Б. С. Братусья и Н. В. Ининой теоретически обосновывается рассмотрение веры как общепсихологического явления, необходимого компонента любой сложно организованной человеческой деятельности. Показаны различия и связь религиозной и нерелигиозной форм веры, их специфика при невротических отклонениях личности, суевериях, предрассудках, фанатизме. Предлагается психологическая классификация форм веры на основе степени их осознанности и активности субъекта веры.

А. Г. Задохин рассматривая роль бессознательного в политических процессах и действиях политиков, отмечает, что политиками зачастую игнори- 
руются знания психологии личности и общества.

В статье Ю. В. Кузнецовой освещена проблема научного метода толкования сновидений в аналитической психологии К. Г. Юнга. Раскрывается сущность символики сновидений в рамках теоретических представлений об архетипах коллективного бессознательного. Рассматриваются ключевые моменты процесса индивидуации как определяющей цели психического развития личности, сформулированные Юнгом.

А. В. Тулиным была выполнена научная работа, посвящённая сравнительной характеристике сознательного и бессознательного в трудах советских и западных психологов. Ценность его труда в том, что посредством сравнения автору удалось, с одной стороны, сопоставить взгляды отечественных и зарубежных психологов, относительно рассматриваемого вопроса, с другой - извлечь из их трудов рациональное зерно в форме нового знания.

В научной статье Т. Н. Березины анализируется явление обмена эмоциями в человеческом общении. Отмечается, что обмен эмоциями является составной частью перцептивной стороны любого акта общения. Утверждается существование трех уровней обмена эмоциями в общении: осознанный - с помощью слов, неосознаваемый - через невербальные составляющие коммуникации (мимику, жесты и т. п.) и бессознательный - посредством обонятельного канала.

В качестве механизма бессознательного обмена эмоциями предполагается существование эмоционально-обонятельного языка. По её мысли бессознательность передачи предполагает, во-первых, эмоции, передаваемые с помощью запахов, могут не осознаваться, но влиять на настроение человека, во-вторых, запахи, передающие эмоции, - не осознаются в качестве ароматов, в-третьих, такая передача не контролируется сознанием. Предполагается, что каждая основная эмоция связанна с конкретным базовым запахом. При переживании человеком такой эмоции изменяется функциональное состояние его организма, что ведет к появлению соответствующего базового запаха. В свою очередь, выделившийся базовый аромат вызывает конкретную основную эмоцию у других людей - ту же самую, что породила его.

Ею также выделяются конкретные связки «эмоция - запах». Утверждается, что подобный механизм может лежать в основе феноменов психического заражения, таких как массовая паника и т.п. Высшие чувства также могут быть составлены с помощью сочетания основных эмоций, посредством сочетания базовых запахов передаваться собеседникам по общению и, соответственно, вызывать у них аналогичные переживания. Такая передача может быть основой эмпатии. 
Научные труды Московского гуманитарного университета 2018 № 3

Феномен психологического времени рассматривается в статье В. А. Микаелян в контексте проблем клинической психологии. Автор обосновывает тезис о том, что особенности психики, соединяющей в себе сознательное и бессознательное, проявляются также в переживании человеком психологического времени. Уточнение этого, временного аспекта функционирования психики позволяет более полно и содержательно представить истоки психических расстройств.

Д. Барг отметил, что Фрейд и представить себе не мог, насколько бессознательные желания и побуждения влияют на то, как мы думаем и действуем. С этим выводом автора следует, безусловно, согласиться по той простой причине, что бессознательные желания и побуждения тесно связаны с эмоционально-волевой структурой личности и таким образом предопределяют конечную судьбу наших мыслей и поступков.

В статье Н. Ю. Якушевой утверждается и обосновывается актуальность и новизна философско-эпистемологического исследования феномена когнитивного бессознательного. Приводится история изучения и основные подходы к философской интерпретации данной проблемы. В заключение статьи автор делает обоснованный вывод о том, что когнитивное бессознательное является важным элементом познания.

В научном труде В. А. Сабадуха подвергнуто сомнению господствую-щее в философии и психологии утверждение «каждый человек - личность». Проанализированы историко-философские и социально-психологические условия его возникновения. Показано, что существенное влияние на его формирование оказало коллективное бессознательное, которое отвергло концепт «личность - принцип бытия». Проанализирована открытая и скрытая мировоззренческая борьба вокруг понятия личности и обоснована концепция иерархического понимания человеческих качеств. Предложенный концепт позволяет вернуть в общественную жизнь принцип духовной иерархии, а в психологии открывает новые возможности в осмыслении соотношения сознательного и бессознательного в человеческой психике и действительности.

Коллективом автором научной статьи обсуждается роль сознания в организации различных видов движения. Доказывается, что якобы непроизвольные движения (тремор) и произвольные движения (теппинг) мало отличаются друг от друга. С позиций стохастики эти два типа движений хаотичны по сути, т. к. статистические функции распределения $\mathrm{f}(\mathrm{x})$ хаотически изменяются.

В рамках новой теории хаоса-самоорганизации предлагаются методы расчета квазиаттракторов и матриц парных сравнений выборок, которые обеспечивают четкие различия между тремором и теппингом, т. е. между 
непроизвольными и произвольными движениями. Сама произвольность, т. е. усиление сознания в организации движений, осуществляется увеличением доли стохастики в сравниваемых подряд выборках треморограмм и теппинграмм испытуемых. Это представляет количественно эффект Еськова-Зинченко в оценке не только организации движении, но и в осуществлении регуляции различных других функциональных систем организма, которые обеспечивают гомеостаз. Роль сознания сейчас (объективно) сводится к усилению доли стохастики в параметрах движений, но при этом хаос превалирует над стохастикой в организации любых движений.

Рассмотрению аналитической психологии К. Г. Юнга посвятил своё научное исследование С. А. Кисилёв. Сформулированные автором выводы способствуют более глубокому пониманию природы структуры сознательного и бессознательного в человеке, опредмеченной в психологии этого известного мыслителя прошлого.

Вслед за С. А. Кисилёвым к аналитической психологии К. Г. Юнга обратились исследователи проблемы Т. Э. Мариносян и Ю. Г. Куровская. В своей статье они предприняли попытку выявить сходство и определить соотношение между понятиями «архетип» и «фрейм», используемыми в аналитической психологии, философской антропологии, аналитической философии, когнитивной лингвистике. Опираясь на основные положения теории аналитической психологии К. Г. Юнга, представляющей архетипы как изначальные образы бессознательного человека, и теории фреймов о том, что знания о мире состоят из структурных ячеек, структур данных, сценарных матриц - фреймов - своего рода энграмм, авторы проводят сопоставительный анализ понятий «архетип» и «фрейм» и делают вывод о том, что у обоих понятий имеются сходные черты с высокой степенью корреляции.

В научной работе Ю. В Бобровой рассматриваются две базовые философско-психологические концепции: сознание и подсознание. В статье анализируется природа человека, которая напрямую зависит от его психических функций. На основе изучения установлено, что сознание и подсознание составляют определенную дуальность человеческого восприятия мира. Проведен сравнительный анализ, как разделение разума на эти два элемента психики, могут влиять на человека, чем они похожи и чем отличаются друг от друга.

В статье Е. В. Александровой и Т. В. Капустиной исследуются архетипы и архетипические образы в сновидениях человека. Для изучения архетипов и их появления в сновидениях была составлена авторская методика. Было выявлено, что разница проявлений архетипов у девушек и юношей отсутствует. Выявлена связь в проявлении архетипов в деятельности человека и его сновидениях. 
В рамках коллективной монографии учёные Н. Е. Горская и В. Е. Глызина опубликовали статью, в рамках которой провели анализ научных концепций зарубежной психологии в изучении самосознания личности. Данная ими сравнительная характеристика позволяет индивидуализировать взгляды различных учёных по опредмеченной проблематике и, таким образом, каждым исследователем при проведении собственных исследований вопроса извлекается из научных трудов этих учёных рациональное зерно.

Завершая проведенное исследование, следует сформулировать некоторые выводы, суть которых сводится к следующему:

a) выявленные в лаконичной форме сущность и содержание проведен-ных научных исследований проблемы сознательного и бессознательного имеет своё непреходящее значение. Оно состоит в том, что дальнейший анализ этой проблемы позволит сфокусировать цели и задачи последующих научных работ на тех аспектах, которые не были затронуты в уже проведённых исследованиях и позволит углубить и расширить горизонты научного видения этой проблемы, эксплицировать её на решение социокультурных проблем современной России;

б) фундаментальный вклад в научную разработку проблемы сознательного и бессознательного внесли такие известные учёные современной России как Ф. В. Бассин, А. Э. Воскобойников, П. С. Гуревич, Р. Ф. Додельцев, Д. И. Дубровский, И. С. Кон, В. М. Лейбин, Н. С. Автономова, В. И. Овчаренко, М. М. Решетников, С. А. Семедов и др.;

в) в период с 2004 по 2017 гг. отдельные аспекты указанной проблемы нашли отражение в научных статьях таких авторов, как, Е. В. Сальникова, В. В. Старавойтов, Т. Рашидова, И. Г. Хангельдиева, А. А. Калмыков, Л. Н. Кубашичева, А. Макинтайр, С. А. Тугуши, И. В. Головачёва, И. А. Куевда, Н. Ю. Хусаинова и А. Р. Гиниятуллина, В. Э. Степанова, Е. М. Уколова и В. Б. Шумской, Б. С. Братусь, Н. В. Инина, А. Г. Задохина, Ю. В. Кузнецова, А. В. Тулина, Т. Н. Березина, В. А. Микаелян, Д. Барг, Н. Ю. Якушева, В. А. Сабадуха, Ю. П. Зинченко, О. Е. Филатова, В. В. Еськова, Т. В. Стрельцова, Т. Э. Мариносян, Ю. Г. Куровская, Ю. В. Боброва, Е. В. Александрова, Т. В. Капустина, Н. Е. Горская, В. Е. Глызина и др.;

г) проблема историографии вопроса сознательного и бессознательного отнюдь не считается окончательно разрешённой в рамках настоящего исследования, хотя мы обратились почти к каждому опубликованному источнику. А это значит, что имеются и другие исследования, требующие краткого, лаконичного анализа их содержания и смысла. Но эту работу можно будет провести в дальнейшем, когда они будут опубликованы и станут доступны для научной общественности. 
Магаррамов Магаррам Дэабраилович - доктор философских наук, профессор, ведущий научный сотрудник Регионального Центра этнополитических исследований Дагестанского научного центра Российской академии наук. Адрес: 367000, Россия, г. Махачкала, ул. М. Гаджиева, д. 45. Эл. адрес: m.magarram@gmail.com

Magarramov Magarram Dzhabrailovich, Doctor of Philosophy, Professor, Leading Research Fellow, Regional Centre of Ethnopolitical Researches, Dagestan Scientific Centre, Russian Academy of Sciences. Postal address: 45, M. Gadzhiyeva St., Makhachkala, Russian Federation, 367000. E-mail: m.magarram@gmail.com

\section{Для цитирования:}

Магаррамов М. Д. Сознательное и бессознательное: к историографии вопроса [Электронный ресурс] // Научные труды Московского гуманитарного университета. 2018. № 3. URL: http://journals.mosgu.ru/trudy/article/ view/740(дата обращения: дд.мм.гг.). DOI: 10.17805/trudy.2018.3.3 